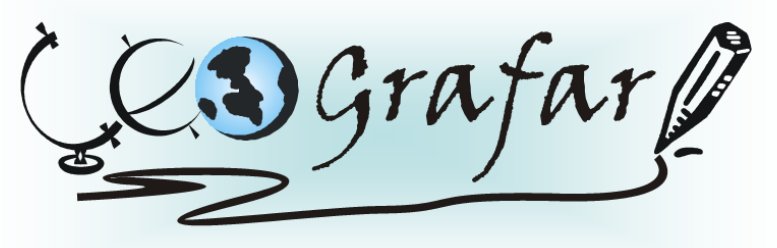

Revista Eletrônica do Programa de Pós-Graduação em Geografia - UFPR

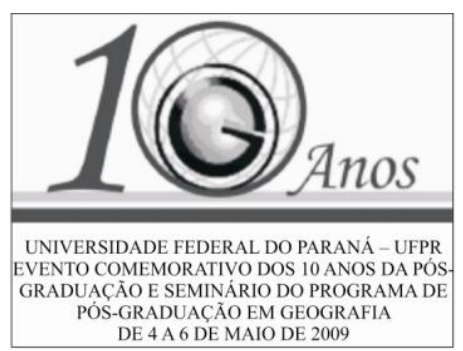

\title{
MODELAGEM DA PRODUÇÃO E TRANSPORTE DE SEDIMENTOS DA BACIA HIDROGRÁFICA DO ALTO RIO NEGRO
}

\author{
RODRIGO MARCOS DE SOUZA ${ }^{1}$ \\ ANA MARIA MURATORI ${ }^{2}$
}

\section{LINHA DE PESQUISA: PAISAGEM E ANÁLISE AMBIENTAL}

A forma de relação predatória com a qual o homem utilizou e continua utilizando os recursos naturais resultou em impactos negativos sobre a natureza e a sociedade. Entre as conseqüências, temos a mudança no regime de produção e transporte de sedimentos de uma bacia hidrográfica. Uma investigação no sistema real, envolvendo medições de todas as variáveis que influenciam a dinâmica de uma bacia hidrográfica é uma tarefa árdua, pois o longo prazo exigido e os custos de medições e monitoramento são grandes empecilhos. Devido a este fato, modelos hidrológicos estão sendo cada vez mais utilizados. Assim, a pesquisa será desenvolvida na bacia hidrográfica do Alto Rio Negro, localizada ao sul do estado do Paraná e ao norte do estado de Santa Catarina, entre as latitudes 2559'29'’S e $26^{\circ} 21^{\prime} 32^{\prime}$ 'S e entre as longitudes $49^{\circ} 10^{\prime} 12^{\prime \prime} \mathrm{W}$ e $49^{\circ} 36^{\prime} 53^{\prime \prime} \mathrm{W}$, com área de drenagem de $3.530 \mathrm{~km}^{2}$. A bacia apresenta diferentes tipos de uso do solo como agricultura, pastagem, florestas, reflorestamentos e adensamento urbano. Através da aplicação do modelo SWAT (Soil and Water Assessment Tool), pretende-se avaliar a produção e transporte de sedimentos na referida bacia, mediante simulação de cenários de uso do solo, oferecendo assim à sociedade alternativas de usos menos impactantes dos recursos naturais da área de estudo. $\mathrm{O}$ SWAT é um modelo matemático de domínio público, desenvolvido em 1996 pelo Agricultural Research Service e pela Texas A\&M University. O modelo é distribuído e permite prever o impacto do uso e manejo do solo sobre o ciclo hidrológico, o transporte de sedimentos e a qualidade da água em grandes e pequenas bacias em um intervalo de tempo longo. Para sua aplicação, o modelo necessita de dados espaciais e séries temporais de dados

\footnotetext{
${ }^{1}$ rmarcos@globo.com

2 Professora orientadora
} 
climáticos. Caso não se disponha das séries, pode-se utilizar a simulação de dados realizada pelo SWAT. O modelo vem sendo utilizado de forma corrente após o seu desenvolvimento em trabalhos acadêmicos e em instituições públicas e privadas.

Palavras-chave: Produção e transporte de sedimentos; modelo SWAT; vazão sólida. 